\title{
PSICOLOGIA SOCIAL NA ESCOLA: AS CONTRIBUIÇÕES DE G. H. MEAD
}

\section{Ruth Bernardes de Sant'Ana Universidade Federal de São João Del-Rei}

RESUMO: Partindo do pressuposto de que as interações sociais vividas pelo sujeito podem favorecer tanto o desenvolvimento de supremos valores éticos quanto a sua degradação social e moral, Mead (1863-1931), reflete o papel da escola na formação do self, instância cognitiva e social a permitir movimentos de autonomia do indivíduo diante do controle imposto pela ordem social e a sua capacidade na tomada de decisões no campo pessoal e político. $\mathrm{O}$ artigo recupera elementos da reflexão meadiana sobre a escola, um autor progressista que defende uma educação democrática para a formação de sujeitos críticos e reflexivos, condição imprescindível para a cidadania crítica.

PALAVRAS-CHAVE: Mead, Interacionismo Social, Escola, Psicologia Social.

\section{SOCIAL PSYCHOLOGY IN THE SCHOOL: THE CONTRIBUTIONS OF G. H. MEAD}

ABSTRACT: The study is based on the assumption that the social interactions experienced by the subject might facilitate both the development of supreme ethical values, as well as the subject's social and moral degradations. Mead (1863 - 1931) reflects on the role of school regarding the formation of self, cognitive and social instances, which allows movements of the individual's autonomy when faced with the control imposed by the social order, and his capacity of making decisions in the personal and political fields. The article rediscovers elements of the median reflection about school. The author is progressive and defends a democratic education for the formation of critical and reflexive individuals, which is an indispensable condition for the growth of analytical citizenship. KEY-WORDS: Mead, Social Interacionism, School, Social Psychology

\section{INTRODUÇÃO}

A distinção da escola como uma instituição educativa e formativa essencial para o sujeito, estabelecida por Mead (1896, 1898, 1910, 1934/ 1967), permite que a sua perspectiva teóricometodológica se apresente como uma referência fundamental para analisar a ação educativa desenvolvida por essa instituição social a ampliar a nossa compreensão acerca do peso das relações sociais no processo de construção do psiquismo, reveladas nas manifestações da inteligência, do pensamento, da criticidade, assim como da ética e dos valores, elementos fundamentais no processo de apropriação da realidade como fenômeno sociocultural na e pela ação humana. Embora concebida em outro tempo e espaço, a obra do autor nos permite compreender o presente por refletir questões que atravessaram o século passado sem uma resposta definitiva. Por esse motivo este artigo $^{1}$ recupera alguns elementos da reflexão de Mead (1863-1931), sobre a escola, um autor progressista que defende uma educação democrática, favorecedora da formação de sujeitos críticos e reflexivos, condição imprescindível para a cidadania crítica.

Tornando a formação do sujeito um objeto central de estudo, o interacionismo de Mead permite considerar o que é problemático no processo interativo e mostrar as tensões que se manifestam no interior das instituições sociais, o que enriquece os estudos da escola.

Recorro a Bronckart para localizar a perspectiva epistemológica que fundamenta a teoria meadiana.O autor (2003) denomina de interacionismo social $^{2}$ uma

"posição epistemológica geral, na qual podem ser reconhecidas diversas correntes da filosofia e das ciências humanas. Mesmo com as especificidades dos questionamentos teóricos particulares e com as variantes de ênfase teórica ou de orientação metodológica, essas correntes têm em comum o fato de aderirem a tese de que as propriedades específicas das condutas humanas são o resultado de um processo histórico de socialização, possibilitada especialmente pela emergência e pelo desenvolvimento dos instrumentos semióticos" (p. 21).

Bronckart (2000) é um autor que nos traz o interacionismo de Mead como ligado a uma matriz de pensamento em ciências humanas que remete a Hegel, Marx, Engels, uma forte tradição materialista 
Sant'Ana, R. B. "Psicologia Social na escola: as contribuições de G. H. Mead"

"que analisava a construção do pensamento consciente humano como um fenômeno paralelo (ou estreitamente articulado) à construção de um mundo sociocultural e que considerava os processos de socialização e os processos de individuação (formação de pessoas individuais) como duas vertentes complementares e indissociáveis do desenvolvimento humano; integrava, numa mesma abordagem, as questões propriamente psicológicas e as questões de educação e de formação" (p. 1).

Mead concebe o processo de formação da individualidade como intimamente relacionado com os processos educativos promovidos pelas instituições educativas. Por isso, encontramos no autor a idéia de que a escola é uma instituição social que proporciona ao educando um conjunto de experiências reveladoras de atitudes da sociedade mais ampla em relação a ele. Ocupando o papel de porta-voz das pautas de condutas da sociedade, a escola se apresenta no pensamento meadiano como uma instituição de socialização, ao oferecer referências fundamentais para a condução do sujeito na sociedade. Ao mesmo tempo, a escola deve buscar o desenvolvimento de um projeto formativo voltado para a aquisição de competências cognitivas necessárias ao pensamento reflexivo. Ambas as ações, socializante e cognitiva, da escola são indispensáveis e indissociáveis para a formação do self ${ }^{3}$, instância nascida de experiências, simultaneamente, cognitivas e sociais.

A psicologia social se interessa pela maneira pela qual o psiquismo é formado e modificado pela interação com os outros. Desse modo, torna-se importante entender como os indivíduos constituem suas significações da realidade para a compreensão da formação do psiquismo e de suas manifestações na vida social, pois

"para Mead, as significações são construídas no interior de diferentes situações de interação entre os indivíduos, o mesmo ocorrendo com as regras que governam a vida social. E uma vez instituídas tais significações e tais regras, estas tendem a anteceder a interação social oferecendo representações antecipadas das situações" (SANT'ANA, 2003c, p. 108).

A análise das interações sociais tem se afirmado enquanto um dos terrenos mais profícuos da psicologia social contemporânea. Ao deslocar o plano de investigação e análise para a interação entre indivíduos e grupos, o interacionismo abre espaço tanto para uma microssociologia quanto para uma psicologia social voltada para os "processos práticos de instituição contínua do social" (ZIOLKOWSKI, 1997, p. 11). O interacionismo social concebe que a ordem social depende de um circuito de interações complexo envolvendo o "aqui e agora" das situações sociais, mas que se liga a uma rede de significações sociais que transcende o encontro face-a-face. Assim, a ordem social se manifesta na interação cotidiana entre os indivíduos, supondo um jogo de interpretação recíproco e contínuo, sujeito ao confronto e a negociação entre interesses diferentes.

A preocupação com uma abordagem voltada para o cotidiano da prática escolar, que desvele as ações dos sujeitos que dele participam, torna o interacionismo uma abordagem promissora no campo dos estudos críticos sobre a educação. O interacionismo social e a etnografia da prática escolar se aproximam ao propor os seguintes princípios básicos para o desenvolvimento do trabalho de investigação: a) tornar o familiar estranho, registrando o que parece óbvio; b) explorar a situação tal como ela é concebida pelos sujeitos dela participantes, levando em conta seus significados e interpretações; c) analisar a relação entre a situação de sala de aula e o seu contexto de inserção;d) construir as hipóteses e os argumentos no interior do trabalho de campo. Essa proximidade temática e metodológica tem favorecido trabalhos que conjugam essas duas perspectivas, perceptíveis nos trabalhos de Sirota (1994) e Woods (1989).

A meu ver, o interacionismo social muito contribui para a investigação da escola enquanto instituição, por permitir a conexão da discussão epistemológica com um conjunto de recursos teóricosmetodológicos a referenciar a análise do cotidiano escolar; interessa-se pelo que as pessoas fazem e como interatuam, suas crenças, perspectivas, valores, motivações e como isso se desenvolve com o tempo e de uma atividade à outra. Assim sendo, torna-se possível apreender uma escola, um grupo particular de alunos ou de professores, a desvelar o sentido das ações materializadas na vida escolar. Por isso, incorporamos de Sirota (1994, p. 11), o postulado de que “... o cotidiano escolar pode ser lido e decifrado através da interação social que toda situação pedagógica gera, ressituada em seu contexto institucional e social".

Para precisar a análise, cada componente da situação pode ser diferençado: os sujeitos em interação; o setting concreto; os significados trazidos para a situação; as características que assume a interação no tempo e no espaço organizacional. Ou seja, o conjunto de elementos mais significativo é desmembrado em unidades, cada qual oferecendo visibilidade ao todo. Desse modo,

"a dinâmica da escola pode ser captada 
não só em suas características recorrentes, mas também em seus processos de oscilações, ambigüidades e perturbações. Assim, o pesquisador pode compreender a realidade estudada em diversos planos de significação social, realizando estudos de maior profundidade. A rotina, com seus rituais, suas regras de funcionamento, bem como os efeitos que tem sobre os indivíduos e as mudanças que nela se produzem são alguns elementos passíveis de análise" (SANT'ANA, 2003b, p. 8).

Localizando a unidade de análise na interação, o interacionismo reconhece que o comportamento observado envolve mais do que as intenções e significações nascidas na interação, pois se trata de um processo dialético de confrontação permeado por significações que transcendem os limites da interação face-a-face. Na verdade, Mead (1934/ 1967) defende que o encontro com o outro, nas instituições sociais, é sempre demarcado pelas expectativas de ação oferecidas pelas pautas de condutas instituídas pela sociedade; porém, ressalta o autor que o confronto de diferentes perspectivas abre possibilidades de mudança e de resolução criativa dos conflitos.

\section{A ABORDAGEM MEADIANA DA ESCOLA}

Por convite do pragmatista ${ }^{4}$ John Dewey, Mead (1863-1931) chega à Chicago em 1894, após ter lecionado na universidade de Michigan. Dois anos após a criação daquela Universidade, onde lecionou psicologia social durante toda a sua carreira, próxima de quarenta anos. É assim que nasce uma das contribuições teóricas mais importantes de psicologia social, que, voltada para a formação humana, refletiu sobre o papel da escola em uma sociedade democrática. Recusando-se a conceber a escola apenas em função dos resultados atingidos, Mead compartilha com os teóricos pragmatistas a concepção de que o conjunto de situações de aprendizagens oferecido pelo professor deve ser considerado pelo como e pelo quanto, defendendo uma visão processual da formação do indivíduo.

Desde os seus primórdios, o pragmatismo se preocupou com a ação exercida pelas instituições sociais sobre os indivíduos, enfatizando o movimento de coação e de resistência a ela no interior dessas instituições. Para seus autores, a ampliação da individualização e a diminuição do peso da tradição e do conservadorismo nas pessoas, poderiam facilitar a libertação dos indivíduos de constrangimentos das instituições tradicionais. Nessa perspectiva, uma socialização mais aberta ao novo favoreceria a criatividade individual e grupal, de modo a possibilitar a criação de instituições sociais mais democráticas. Em proximidade com esta perspectiva, Mead (1934/ 1967) afirma

"um movimento de oposição entre uma certa potência ativa do indivíduo e injunções sociais, em que um pode transformar o outro, sem que seja possível prever um resultado absoluto no final do processo. Daí a importância de uma educação democrática para a democratização da sociedade, pois isso estimularia a formação de um indivíduo mais autônomo, menos tolhido na sua potência ativa e mais aberto à participação social, necessária à renovação da sociedade e de suas instituições. Em outras palavras, para que as pessoas tratem de assuntos sociais e pessoais sob a ótica dos direitos e das normas democráticas, faz-se necessário que desenvolvam as competências necessárias a isso, cultivadas desde criança, por meio de interações proporcionadas por seu mundo social" (SANT'ANA, 2003c).

Para Mead, a experiência escolar por excelência deve se alicerçar na experimentação, pois esta permite ao indivíduo perceber, viver e manipular, para assimilar a seus esquemas de compreensão, de avaliação e de ação, os fenômenos da natureza, as relações entre coisas, pessoas e entre elas e objetos. É essa a idéia que unifica o seu pensamento sobre a escola, do "jardim de infância" à universidade. Sua ênfase incide em um "método experimental", em que o sujeito se depara com os problemas e procura resolvêlos usando as competências cognitivas e sociais à sua disposição, que não se resume à situação de laboratório na medida em que englobam também o experimento com as experiências humanas e sociais propiciadas pelas interações sociais entre os indivíduos.

No "jardim da infância", experimentar é brincar e jogar. Além da experiência lúdica ser uma forma muito privilegiada de encontro do sujeito com as atitudes da comunidade, o "outro generalizado" que se dá mediado pelo grupo social participante nessa forma de ação social coletiva, favorece ao mesmo tempo o desenvolvimento cognitivo, pois o jogo e a brincadeira são atividades sociais que retiram do fluxo de relações sociais os elementos que os compõem, buscando dar-lhes uma síntese lógica, cognitiva, ética e, conforme o caso, afetiva. Segundo SASS (1992a, p. 205) a formação do "outro generalizado" permite ao ser humano "internalizar conscientemente o mundo 
exterior e suplantar a si mesmo, convertendo a si mesmo, como consciência de si, no seu outro", ao permitir o diálogo interiorizado. Ou seja, por meio da reflexão com o "si mesmo", endereçando-se a outro sujeito, existente ou abstrato, o indivíduo pode ampliar a consciência de seus atos, problematizando suas experiências.

Na universidade, experimentar é utilizar o método científico para a solução de problemas. Mead critica a escola de ensino médio de seu país porque ela parte da idéia de que o educando primeiro deve compreender as diferentes linguagens utilizadas em cada disciplina científica para depois formular e resolver problemas (Sass, 2000), de modo que a experimentação só tem espaço garantido na universidade. Para Mead, aí reside a causa do fracasso da educação, pois a relação do aluno com o conhecimento assume um caráter fragmentário e intelectualista, destituindo-se de sentido concreto.

\section{A NOÇÃO MEADIANA DE EXPERIÊNCIA E A ESCOLA}

Para Mead, a experiência da criança é socialmente construída, nascendo de diferentes atos dela com diversas pessoas na produção de qualquer atividade social. Para o autor as relações mais significativas de exploração e conhecimento de objetos são mediadas pela ação de um outro, que na medida em que interage com a criança busca definir as significações das experiências.

Compreendo que embora as experiências formadoras sempre impliquem na presença de um outro, presente ou imaginário, é em última instância algo individual. Duas crianças vivendo a mesma situação de interação não necessariamente vivem a mesma experiência, o que faz com que na escola as crianças vivam uma seqüência de experiências susceptíveis de singularidade, pois os sentidos dados às atividades, a coloração afetiva e relacional pode diferir conforme o sujeito. Portanto, a interpretação da experiência pela criança depende não somente da situação objetiva, mas da forma como o indivíduo a percebe, a vive, a experimenta, a utiliza, a assimila a seus esquemas de compreensão, de avaliação e de ação. Destarte, a experiência não é jamais dissociável do sentido e da implicação dados pelo sujeito que a vive, o que dificulta uma análise puramente externa.

Extrapolando este raciocínio para a vida escolar, apesar de considerarmos que um dado evento pode não ser igualmente significativo para todas as crianças de uma mesma turma, isso não impede a reflexão sobre o quanto ele favorece ou não a formação de um sujeito autônomo e reflexivo, pois a teorização sobre tais experiências, construídas pelo campo de conhecimento nos auxilia a identificar aquelas mais significativas para análise.
Partimos do pressuposto que o educador organiza no espaço e no tempo atividades destinadas à criança a oferecer significações para os objetos, as pessoas e situações. A organização e realização das atividades no tempo nos indicam a variedade de experiências e as intenções educativas que definem a rotina, indicando-nos as competências cognitivas e sociais em desenvolvimento pela escola.

O progressivo processo de formação do self aparece intimamente ligado à ampliação das competências comunicativas da criança, razão pela qual o processo de aquisição da linguagem é um aspecto dele indissociável. Para Sass (1992a), a linguagem é uma condição imprescindível para o indivíduo "controlar a sua ação em relação ao mundo, constituindo-se, nesse sentido, em componente fundamental da individuação" (p. 142).

Ao depender das interações sociais, ocorridas no tempo e espaço, para se constituir, o self apresenta as características de uma organização temporal, capaz de articular passado, presente e futuro. A memória, enquanto elemento presente no self, atualiza as experiências vividas oferecendo a possibilidade de encontro entre o passado e o presente na projeção do futuro. Com o desenvolvimento da abstração, a presença do outro concreto para a concretização das experiências mais significativas deixa de ser necessária, se tornando possível o desenvolvimento das trocas e comparações entre concepções e práticas de origens culturais diversas, no diálogo interno com o "outro generalizado". Essa é a aposta meadiana, de que as experiências do sujeito permitam uma certa autonomização do funcionamento do pensamento, que se torna capaz de significar e ressignificar as palavras e as coisas, o que parece constituir a condição necessária para que a pessoa possa intervir verdadeiramente no processo de desenvolvimento dos seus grupos mais significativos de pertencimento; que ela não se limite a uma simples reprodução das aquisições culturais de origem, mas que ela compartilhe ativa e criticamente o processo coletivo de realização de construções coletivas.

Experimentar as diferentes posições que pessoas e objetos podem ocupar no espaço, seus movimentos, reversões de lugar e mudanças de direção pode ocorrer por meio de jogos e brincadeiras, interação social aberta para a diversidade de relações físicas e sociais. O autor remete a uma articulação entre desenvolvimento cognitivo e interação social procurando mostrar que não são os avanços cognitivos que produzem a capacidade de interação social, e sim o seu oposto.

O jogo e da brincadeira, por serem mecanismos de aprendizagem próprios ao mundo da infância, favorecem a formação do self, pela 
incorporar e organização de novos conteúdos de experiências, visto que

"em Mead, a lógica do jogo torna possível uma dada organização do self que permite assim a coordenação de um conjunto de experiências sociais em um todo unitário. Desse modo, o jogo é fundamental na formação do self, visto que é a experiência do jogo que oferece a possibilidade de apropriação organizada das alternativas postas aos sujeitos pelas diferentes experiências sociais" (SANT'ANA, 2003a, p.50).

A preocupação de Mead com o papel do lúdico no desenvolvimento integral do indivíduo se insere em uma problemática que veio marcar o surgimento da educação moderna e que continua atual. Porém, é na pré-escola e na creche que o tema do lúdico se apresenta com maior força, pois a preocupação com o lugar ocupado pelos jogos e brincadeiras na vida da criança pequena e a importância a eles atribuída por diversas tradições pedagógicas têm acentuado a relevância de trabalhos de investigação sobre o tema. Nos trabalhos de fundadores da pré-escola, o lúdico já aparece como essencial, criando uma tradição de pensamento que se estendeu pelo mundo. Mead (1934/ 1967) acentua a importância da brincadeira e dos jogos na formação do self nas vivências das interações sociais cotidianas, defendendo uma educação moderna, em que tais atividades lúdicas estejam presentes como um elemento fundamental na constituição de um sujeito autônomo, ético e transformador de seu meio social.

Considero que a concepção básica de autonomia, a dar sentido à obra do autor, exige algum espaço para situações menos estruturadas e com aberturas ao novo. Elas não apelam a uma única solução, permitindo saídas criativas para a criança, o que as torna fundamentais ao exercício da refletividade, base da autonomia. Ao oferecer à criança situações menos reguladas, o jogo e a brincadeira são modos privilegiados de interação social para a autonomia, permitem à criança entrar em contato com o mundo social e reinventá-lo, transformá-lo, sem temor das conseqüências que poderão advir.

É nessa experimentação promovida por determinadas modalidades de interação social, o jogo e a brincadeira, por exemplo, que ocorrem novas conexões entre diferentes elementos que não necessariamente recompõem sua unidade original. $\mathrm{O}$ resultado permite a imprevisibilidade, a composição e a recomposição constante das relações entre as coisas, as pessoas, entre elas e as coisas. Assim, propiciam experiências sociais capazes de permitir a internalização da realidade e de transformar a organização cognitiva.

Mead concebe a evolução humana como o processo, em termos gerais, em que a experiência do indivíduo se aproxima da organização da pauta geral de conduta do grupo social de pertencimento. Agir é, para o autor, a condição primeira para a constituição de um mundo humano, pois é por meio da ação diferenciada que se constroem referenciais universais a orientar as condutas dos indivíduos, ou seja, nascem significações comumente partilhadas. Desse modo, ação é a forma primeira de confrontação com a realidade, permitindo a formação da consciência, do pensamento e da linguagem ao mesmo tempo, pois "o ato social engendra o campo da significação" (SASS, 1992a, p. 158). Por essa razão, consideramos importante pensar sobre o agir na escola, pois, para Mead, uma ação reflexiva é uma ação distintiva de dimensões da realidade, em que o indivíduo passa de um registro a outro, fazendo arranjos necessários à compreensão e à ação acerca daquilo que o perturba.

A leitura do autor me leva a defender que a estrutura social referencia, mas não determina, as pautas de conduta do indivíduo, posto que ela também é sujeita a múltiplas perturbações, de modo que os efeitos desse encontro entre indivíduo e sociedade não são totalmente previsíveis.

Mead (1934/1967) defende que muito antes do uso da palavra, a criança já revela certas competências que lhe permitem participar do mundo social ajustando as suas atitudes às demandas do outro e vice-versa. Portanto, a criança, mesmo nos seus primeiros anos de vida, reponde a um conjunto de expressões gestuais e verbais dos seus parceiros, tais como: postura e expressões vocais não verbais (grito, choro, balbucio, sorriso etc.). Porém, o verbo assume o papel fundamental de "mediador no desenvolvimento do pensamento e da consciência" (SASS, 1992a, p. 152) estando no centro da reflexão sobre a formação do sujeito. Assim sendo, a criança é vista como progredindo da comunicação gestual para a comunicação oral, a lhe permitir a capacidade de construção de significações ao utilizar palavras nas suas relações sociais, pois "a linguagem verbal, em que o pensamento se faz verbo e o verbo se faz pensado, é a etapa superior de um processo originalmente prélinguístico, cujo início pode ser localizado nos gestos" (SASS, 1992a, p. 152).

Devemos reter que a escola enquanto instituição social tem uma função social que a distingue de outras. Para Mead, a escola deve ser um espaço de convivência democrática assumindo as características de instituições abertas, formadoras de sujeitos capazes de modificar as instituições sociais, democratizando-as. Isso significa torná-la um local de trocas de experiências sociais das crianças entre si 
e entre elas com os adultos, em um processo reflexivo e aberto. Discutindo a importância da teoria de Mead para a reflexão sobre a educação, Sass (2000) diz "No sobra recordar que esos temas, bajo la óptica del pragmatismo, reposan sobre las nociones: a) escuela, comprendida como institución social que proporciona al alumno de manera peculiar un conjunto de actitudes de la comunidad/ sociedad/cultura; o sea, escuela es un otro generalizado; b) experiencia, entendida como experiencia inteligente que conduce a la reflexión; es la base para organizar el currículo escolar, propiciando al alumno la adquisición de los métodos de investigación científica y su inserción, cada vez más compleja, como miembro de la sociedad y como ciudadano. Educación, experiencia, ciencia y democracia son indisociables, según los pragmatistas, para constituir el nuevo hombre" (p. 136).

Segundo Sass (2000), Mead rejeita uma educação baseada no método herbartiano, a pensar a criança apenas como massa perceptiva a assimilar determinados conteúdos escolares, desconsiderando a sua participação em processos de relações com os outros, consideradas as experiências mais ricas na formação do self, ao dizer:

"Se nos voltarmos para o nosso sistema de educação verificamos que os componentes do currículo têm sido apresentados como perceptos (percepts) capazes de ser assimilados, pela natureza de seu conteúdo, por outros conteúdos da consciência, e o método indicado tem sido aquele que esses componentes podem ser mais favoravelmente preparados para tal assimilação. Este tipo de tratamento psicológico do material e da aula é imediatamente reconhecido como método herbartiano. É um tipo de psicologia que é associacionista. Seus críticos acrescentam que é intelectualista. Em todo caso não é uma psicologia social, visto que a criança não é considerada como uma personalidade [self] entre outras personalidades [selves]; é considerada como uma massa aperceptiva [apperceptions masse]. As relações da criança com os outros membros do grupo nem encontram sustentação imediata no material, nem com o aprendizado dele. O banimento pela escola tradicional das atividades de jogos e de quaisquer atividades adultas em que a criança poderia tomar parte como uma criança, isto é, o banimento do processo em que a criança pode ter consciência de si mesma a partir da relação com os outros, significa que o processo de aprendizagem tem tão pouco conteúdo social quanto possível (MEAD, 1910, p. 689, apud SASS, 2000, p. 5859).

Mead crítica o intelectualismo na educação, caracterizado pela sua ênfase em materiais voltados para a instrução formal, cujos conteúdos se mostram destituídos de relação com a realidade vivida pela criança. Além disso, por não enfatizar a participação da criança em atividades de jogo e brincadeira, bem como outras atividades oferecidas por adultos, em que ela possa experimentar suas próprias teorias, o seu processo de organização da experiência, bem como o caráter social e socializador da educação, se perdem.

Lembra-nos Sass (2000) que Mead coloca como saída para romper com essa concepção intelectualista do processo de educação, a escola receber o aporte de uma psicologia social, enquanto ciência que

"reconozca los procesos de adquisición del conocimiento, de atención y valorización en términos emocionales, como capaces de ser investigados en el contexto de las relaciones entre personas, bajo la óptica de la conciencia social" (p. 138).

Portanto, uma escola baseada em uma psicologia intelectualista, que não consegue oferecer à criança experiências que abarquem relações sociais entre as pessoas, mostra-se inadequada no exercício de sua função socializadora, não se apresentando como um lugar privilegiado para contribuir para a formação do sujeito reflexivo.

\section{CONSIDERAÇÕES FINAIS}

Mead se preocupa com a articulação entre o vivido e o ético na formação do sujeito. Para o autor é por meio de experiências grupais de solidariedade que os sujeitos podem aprender a sua importância para o convívio social e não através de um discurso que fala em solidariedade, mas estimula a competição desenfreada entre as pessoas. Isso nos leva a supor que o educador se torna importante na oferta de uma orientação ética ao desenlace dos conflitos oriundos da pluralidade de referências sociais portadas pelos alunos, que se expressam na escola de diversas formas, com vistas à ampliação do espaço de comunicação e do aprofundamento dos argumentos éticos, políticos 
e culturais pelos diferentes grupos presentes no convívio escolar.

A compreensão de que a atribuição de significados aos objetos da experiência física e social não ocorre fora de quadros ideológicos, valorativos, políticos e éticos presentes na sociedade mais ampla e que esse é o elemento central na formação do sujeito é o que devemos refletir no campo da educação. A linguagem que escolhemos para falar da experiência, os elementos que buscamos significar e ressignificar na dinâmica interacional que compõe nossa prática educativa cotidiana deve ser objeto de uma reflexão crítica constante (GIROUX E MCLAREN, 1993).

A linguagem que utilizamos já está carregada de significações da realidade tecidas no transcorrer do processo histórico. Os objetos que se apresentam ao sujeito são impregnados pelas relações sociais que permeiam o comparecimento de tal objeto à experiência, processo do qual nascem as significações da realidade.

Desse modo podemos conceber que a experiência fala de si mesma por meio de uma relação complexa com a vida social, na medida em que a linguagem se interpõe no processo de conhecimento do mundo. Trata-se de um movimento em que a linguagem ao falar da experiência sempre se referencia em atos nomeadores nascidos em meio a outras experiências sócio-culturais do passado, forjadas por diferentes grupos sociais, mas que não necessariamente aparecem enquanto tal quando para os agentes que a utilizam para a significação de experiências dadas no presente.

É na relação entre a linguagem e a experiência que as significações da realidade são construídas. A experiência só ganha um sentido crítico quando concebemos a sua significação em conexão com processos antecedentes de nomeação que se impuseram na linguagem e que circulam na vida social. Com isso, podemos refletir que os aspectos mais significativos da realidade são objetos de disputa em torno de suas significações. Isso exige a consideração que as lutas de classes, gêneros, raça e idade também envolvem contestação de significações que perpassam a vida social e que sustentam relações sociais assimétricas, hierárquicas, de dominação e exploração.

Em uma sociedade excludente e desigual o uso da linguagem pode sustentar relações de subordinação, opressão e exploração ao interpelar a experiência por meio de um discurso modulado para atingir o consenso ideológico dos dominados, que ocorre quando da adesão e da cooperação voluntária dos mesmos na manutenção de significações da realidade que reforçam a dominação. Nesta perspectiva, uma educação para a democracia deve contribuir para a veiculação de significações da realidade que não se rendam ao discurso discriminatório, hierárquico e excludente que circula na sociedade em busca da hegemonia discursiva.

Atualmente, a organização social neoliberal facilita a fragmentação da experiência vivida, cimentando um discurso hegemônico acerca da realidade que justifica a manutenção da desigualdade, da dominação e das hierarquias sociais. De acordo com a lógica do pensamento meadiano o movimento de oposição a isso exige o construir de experiências grupais que além de se confrontarem com o discurso dominante permitam a restauração de experiências democráticas e cooperativas, que sirvam de referências para a vida na sociedade. Assim, cabe ao educador buscar que tais experiências favoreçam a expressão social da luta pela atribuição de novas significações à realidade social e, que, possam atingir os estudantes no momento mesmo das construções de suas significações mais importantes da experiência social.

A experiência pode se ajustar às significações já formadas ou pode transformar a linguagem para que esta renomeie e ressignifique aquela. Desse modo se torna uma possibilidade real a linguagem se render às provocações trazidas pela experiência, produzindo, com isso, uma nova interpretação da realidade. O sujeito, em confronto com a experiência concreta, pode acolher uma nova forma de conceber a realidade que foge das significações instituídas, afirmando, assim, a possibilidade instituinte do real.

\section{NOTAS}

${ }^{1}$ Textos que apresentam maiores informações sobre a biografia do autor foram produzidos por Joas (1985), Sass (1992) e Farr (1998).

${ }^{2}$ Bronckart inclui a perspectiva sócio-histórica de Vigotski na matriz do interacionismo social.

${ }^{3} \mathrm{O}$ self, conceito-chave no trabalho de Mead, define o nível de autonomia do indivíduo diante do controle imposto pela ordem social e a sua capacidade na tomada de decisões no campo pessoal e político, pois abrange a dimensão reflexiva do sujeito, nascida da comunicação significativa com os outros, que o capacita a tomar a si mesmo como um objeto. O traço característico do self, segundo o autor, é a autoconsciência, o que significa refleti-lo como cognitivo e social mais isso não significa que as dimensões emocionais, afetivas ou inconscientes, não estejam presentes no indivíduo, ao mesmo tempo.

${ }^{4}$ Apresentando uma enorme preocupação com a experiência e os interesses do aluno, o pragmatismo se liga a um movimento de renovação da escola que os aproxima do "escolanovismo" cujo maior impacto ocorreu na educação infantil e no ensino primário.

${ }^{5} \mathrm{O}$ "outro generalizado" nasce da abstração e 
internalização das pautas de condutas mais significativas dos diversos "outros" com os quais o sujeito interagiu anteriormente; uma síntese própria tanto das situações sociais oferecidas pela vida social mais ampla quanto das saídas encontradas pelos sujeitos nas situações de interação, a compor assim o self.

\section{REFERÊNCIAS}

BRONCKART, J-P. Atividades de linguagem, textos e discursos. São Paulo: Educ, 2003.

BRONCKART, J-P. Os processos de socialização: Ultrapassando o determinismo cultural. In: CONFERENNCIA INTERNACIONAL DE PESQUISA SOCIOCULTURAL, 3, Campinas, 2000. Disponível em www.fae.unicamp.br/br2000/indit.htm. Acesso em dezembro 2004.

FARR, R. M. As raízes da psicologia social moderna. Petrópolis: Vozes, 1998.

GIROUX, H. A; MCLAREN, P. Linguagem, escola e subjetividade: elementos para um discurso pedagógico crítico. In: Educação e Realidade, Porto Alegre, 18(2): 21-35, jul/dez. 1993.

JOAS, H. G. H. Mead: A contemporary re-examination of this thought. Cambridge, Massachusetts: The MIT Press, 1985.

MEAD, G. H. Mind, self and society. Chicago: The University of Chicago Press. 1934/1967. Disponível em < http://spartan.ac.brocku.ca/Iward/>. Acesso em agosto de 2002.

MEAD, G. H. The relation of Play to Education. University Record 1, n. 8, p. 141-145, 1896. Disponível em <http://spartan.ac.brocku.ca/Iward/ . Acesso em agosto de 2002.

MEAD, G. H. The child and his environment. Transaction of the Illinois Society for Child-Study 3, p. 1-11, 1898. Disponível em <http:// spartan.ac.brocku.ca/Iward/>. Acesso em Agosto 2002.

MEAD, G. H. The psychology of social consciousness implied in Instruction. Science 31, p. 688-693, 1910. Disponível em <http://spartan.ac.brocku.ca/Iward/ $>$. Acesso em agosto de 2002.

SANT'ANA, R. B. Experiências formativas em pré-escola: sob a perspectiva da psicologia social de G. H. Mead. 2002. Tese (Doutoramento em Psicologia Soci- al). Pontifícia Universidade Católica, São Paulo, 2002. SANT'ANA, R. B. A experimentação, o jogo e a brincadeira como experiências formativas na teoria social de Mead. Revista Brasileira de Crescimento e Desenvolvimento Humano, São Paulo, 13(2), p. 44-52, 2003a.

SANT'ANA, R. B. A pesquisa interacionista e a investigação da escola. Revista Vertentes, São João del-Rei, 22, p. 07-18, 2003b.

SANT'ANA, R. B. Interface entre a Psicologia Social e a Educação Infantil: as contribuições do interacionismo de G. H. Mead. In: Psicologia Social e Direitos Humanos. Belo Horizonte: Programa de Pós-Graduação em Psicologia - UFMG - Edições do Campo Social, p. 93-110, 2003c.

SASS, O. Crítica da razão solitária: a psicologia social de George Herbert Mead. 1992. Tese (Doutoramento em Psicologia Social). Pontifícia Universidade Católica, São Paulo, 1992a.

SASS, Odair. Psicologia social y educación: la perspectiva pragmática de George Herbert Mead. Revista Educación y pedagogía, v. 12, n. 26-27, 1992b, p. 125-139.

SASS, O. Educação e psicologia social: uma perspectiva crítica. São Paulo em perspectiva (14) 2, 2000.

SIROTA, R. A escola primária no cotidiano. Porto Alegre: Artes Médicas, 1994.

WOODS, P. La escuela por dentro. La etnografia en la investigación educativa. Buenos Aires: Madrid: Editora Paidos, 1989.

ZIOLKOWSKI, J. M. de Q. M. Linteractionnisme symbolique. Rennes: Presses Université de Rennes,1997.

Ruth Bernardes de Sant'Ana é membro do Laboratório de Pesquisa e Intervenção Psicossocial (LAPIP) e Docente vinculada ao Departamento das Psicologias (DPSIC), ambos da UFSJ.O endereço eletrônico da autora é ruthbs@ufsj.edu.br
Ruth Bernardes de Sant 'Ana
Psicologia social na escola:
as contribuições de G. $H$. Mead.
Recebido: 21/07/2004
$1^{\text {a }}$ revisão: 28/02/2005
Aceite final: 17/06/2005 